Received: November 22, 2017

\title{
Research on the Educational Structure of International Students from the Host Country of China's Overseas Engineering Projects
}

\author{
Songlin Wang ${ }^{1}$ \\ Hohai University
}

\author{
Zhen Tang ${ }^{2}$ \\ Hohai University
}

\begin{abstract}
The education of international students in China is an important way for the successful implementation of China's overseas projects in the host country. Firstly, this research adopts the principal component analysis method to construct the index system for the evaluation of the educational structure of international students from the host country of China's overseas engineering projects and then makes a country selection for the host country of China's overseas engineering projects. Then it evaluates and analyzes the educational structure of international students in China. The study finds that the educational structure of international students in China is characterized by "single core and multi-level". Finally, it puts forward the development countermeasures for the educational structure of international students in China from the host country of China's overseas engineering projects.
\end{abstract}

\section{Keywords}

China's Overseas Engineering Project • International Students in China • Educational Structure

\footnotetext{
*We gratefully acknowledge the financial support from National Studying and Planning Program for Philosophy and Social Science of China (No.16BGL013).

${ }^{1}$ Correspondence to: Songlin Wang. Business School of Hohai University, Nanjing 210000, China. Email: 490040716@qq.com

${ }^{2}$ Business School of Hohai University, Nanjing 210000, China. Email: tangzh@ hhu.edu.cn 
In the context of globalization and the reform and opening up, engineering enterprises in China have stepped out of the country to compete with enterprises in other countries in order to alleviate the pressure of overcapacity and the competition of international enterprises and satisfy the needs for self-development. In recent years, with the implementation of strategies such as "going out" and "the Belt and Road", Chinese enterprises have good development momentum in the international engineering market and their market share has increased year by year (Chen \& Eliman, 2016).

However, China's overseas projects are not smooth in the implementation process. Due to the lack of international development experience, there are many difficulties for the projects of China's engineering enterprises in the host country (He, 2007). The root cause for this situation is the lack of localized talent (Song, 2007). First, the employment of localized talents can effectively reduce the operational risk caused by language, culture and political issues. Secondly, it helps to reduce the high staff management cost associated brought by external assignments. International students in China are a potential and important source of talents for China's engineering enterprises and they are also a huge pro-China strength. The international students in China will be able to play an important role in promoting the smooth implementation of China's overseas engineering projects.

Due to the objective factors such as the large number of countries, large time span, sample dimension complexity and large capacity involved in the education of international students from the host country of China's overseas engineering projects, the principal component analysis method is used in this paper to construct an index system for the evaluation of the educational structure of international students in China to explore the development level, regional differences and dynamic variation of the education of international students from the host country of China's overseas engineering projects and propose a development strategy for the further optimization of the educational structure of international students in China.

\section{Construction of the evaluation index system for the educational structure of international students in China}

As the internal constitutional state of the education system, educational structure is an important factor to improve the quality and efficiency of education (Hu, 2017). The analysis of the connotation of the educational structure of international students in China and the determination of scientific evaluation index system and method are the basis for obtaining objective evaluation conclusions. The structuralist psychologist Easley, Piaget \& Rosin (1980) argues that "structure" is holistic, transformative, and self-adjusting. The pedagogy defines the educational structure as "the proportion, relationship and combination of each part in education" Previous studies have shown that there are many dimensions in the educational structure of international students in China. However, the educational scale, the structure and hierarchical structure of the origin of students and the funding source of international students in China constitute the core elements of educational structure. Based on the preliminary research conclusions and the availability of data, the scale structure, hierarchical structure and scholarship structure are determined as the main dimensions for analyzing the educational structure of international students from the host country of China's overseas engineering projects. 
In order to scientifically reflect the actual situation of the educational structure of international students from the host country of China's overseas engineering projects, it is necessary to further determine the connotation and evaluation indexes of the scale structure, the hierarchical structure and scholarship structure (Hu \& Yu, 2018; Han, 2017). First, the scale structure in this study mainly refers to the total number and distribution of students from the host country of China's overseas engineering projects and its basic characteristics and trends.

Secondly, the hierarchical structure refers to the number and proportion of international students from the host country of China's overseas engineering projects in all overseas students of academic degree and nonacademic degree studying in universities or research institutions in China. Overseas students of academic degree include junior college students, undergraduates, postgraduates and doctoral students; overseas students of nonacademic degree mainly refer to visiting students (including general visiting students, advanced visiting students and short-term overseas students). The hierarchical structure is a key index to measure the level of education development of international students in China. Among them, the education of overseas students of academic degree, especially the scale and cultivation quality of postgraduates and doctoral students, is an important index reflecting the education level of international students in China.

Finally, the scholarship structure mainly refers to the proportion of scholarship awarded by Chinese government in different levels of international students from the host country of China's overseas engineering projects, including the number of scholarships for undergraduates, the number of scholarships for master and doctoral students and the number of scholarships for visiting students. Based on the above analysis, this study establishes the index system for the evaluation of the educational structure of international students from the host country of China's overseas engineering projects as the basis for quantitative analysis and comprehensive evaluation (see Table 1).

Table 1

Evaluation Index for the Educational Structure of International Students from the Host Country of China's Overseas Engineering Projects

\begin{tabular}{|c|c|c|}
\hline Target & Evaluation structure & Evaluation index \\
\hline \multirow{8}{*}{$\begin{array}{l}\text { Educational structure of } \\
\text { international students from the } \\
\text { host country of China's overseas } \\
\text { engineering projects }\end{array}$} & Scale structure & $\begin{array}{l}\mathrm{X}_{1} \text { : total number of international students } \\
\text { in China }\end{array}$ \\
\hline & \multirow{4}{*}{ Hierarchical structure } & $\mathrm{X}_{2}$ : number of junior college students \\
\hline & & $\mathrm{X}_{3}$ : number of undergraduates \\
\hline & & $\mathrm{X}_{4}$ : number of mater and doctoral students \\
\hline & & $\mathrm{X}_{5}:$ number of visiting students \\
\hline & \multirow{3}{*}{ Scholarship Structure } & $\begin{array}{l}\mathrm{X}_{6}: \text { number of scholarships for } \\
\text { undergraduates }\end{array}$ \\
\hline & & $\begin{array}{l}\mathrm{X}_{7} \text { : number of scholarships for master and } \\
\text { doctoral students }\end{array}$ \\
\hline & & $\begin{array}{l}\mathrm{X}_{8} \text { : number of scholarships for visiting } \\
\text { students }\end{array}$ \\
\hline
\end{tabular}

\section{Country selection of the host country of China's overseas engineering projects}

Through the statistics of the market share and growth rate of China's overseas engineering projects since the 21st century. This paper selects 63 countries distributed in Asia, Africa and Latin America as research objects (Yang \& Lu, 2018). 
Wang, Tang / Research on the Educational Structure of International Students from the Host Country of China's Overseas ...

Asia. China's engineering enterprises have fully explored Asia, this "native market". Due to geographical advantages, they have developed well in neighbouring countries such as Pakistan, Malaysia, Singapore and Vietnam in recent years. As an "oil kingdom", Saudi Arabia ranks first in the world in terms of oil reserves and production. In such country attracting global attention and contended by many international engineering enterprises, China's engineering enterprises stand out from many top international engineering enterprises and win the favour of Saudi people with high standards and excellent technology. From the perspective of geographical location, Saudi Arabia is located in the hub of China's "the Belt and Road" and plays a vital role in the "going out" of China's engineering enterprises.

Africa. According to statistics, in 2016, the top five countries of contract engineering volume completed in Africa were Algeria, Ethiopia, Kenya, Angola and Nigeria. In Algeria alone, the engineering volume completed in 2016 was as high as $\$ 8,432.21$ million, accounting for $16.39 \%$ of the market share in Africa in that year, becoming the country with the largest market share in African market for Chinese contractors.

Latin America. Due to the geographical distance and huge differences in religion and culture, the market share of China's overseas project contract is low in Latin America and the distribution of regional market is relatively concentrated. In 2016, the top three countries of engineering volume completed were Venezuela, Ecuador and Brazil, whose market share was $25.42 \%, 19.69 \%$ and $13.5 \%$ respectively, accounting for nearly $60 \%$ of the turnover in Latin America. Due to rich energy resources in Latin America, China has achieved breakthroughs in terms of the infrastructure construction and development and utilization of new energy resources in Latin America in recent years (Zhang, 2007).

\section{Evaluation results and analysis of the educational structure of international students in China}

\section{Evaluation of the educational structure of international students in China}

For the study of complex social phenomena, the statistics tend to use the principal component analysis method for the reduction of dimensionality. It can convert multiple variable indexes into a few independent principal components to replace the original variables, thus obtaining more scientific and effective data information. The education evaluation involved in this study is rather complicated, including 63 countries. The time span is from 2010 to 2017 and each year contains 8 development indexes shown in Table 1. According to the basic principle of principal component analysis, the score and comprehensive ranking of the educational structure of international students from the host country of China's overseas engineering projects are obtained mainly through the following 3 steps.

The first is to establish a correlation coefficient matrix for the educational structure indexes of international students in China.

The second is to extract the main component of the evaluation index of the educational structure of international students in China. According to the Kaiser rule thumb, the characteristic value and cumulative contribution rate of the main components are measured, as shown in Table 2. 
Table 2 (a)

Main Component Eigenvalues and Cumulative Contribution Rate of the Educational Structure of International Students in China Education from 2010 to 2013

\begin{tabular}{|c|c|c|c|c|c|c|}
\hline \multirow[b]{2}{*}{ 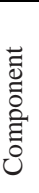 } & \multicolumn{2}{|c|}{2011} & \multicolumn{2}{|c|}{2012} & \multicolumn{2}{|c|}{2013} \\
\hline & 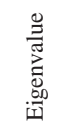 & 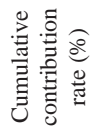 & 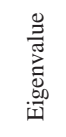 & 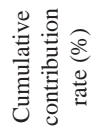 & 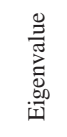 & 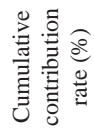 \\
\hline 1 & 4.62 & 61.85 & 4.84 & 59.85 & 4.54 & 61.93 \\
\hline 2 & 1.13 & 70.90 & 1.08 & 75.53 & 1.08 & 70.20 \\
\hline 3 & 0.95 & 84.18 & 1.01 & 84.96 & 0.95 & 82.27 \\
\hline 4 & 0.55 & 94.07 & 0.65 & 90.36 & 0.45 & 92.51 \\
\hline 5 & 0.41 & 98.37 & 0.47 & 96.94 & 0.33 & 96.58 \\
\hline 6 & 0.21 & 98.93 & 0.28 & 98.76 & 0.25 & 99.50 \\
\hline 7 & 0.05 & 100.00 & 0.06 & 100.00 & 0.01 & 100.00 \\
\hline 8 & 0.00 & 100.00 & 0.00 & 100.00 & 0.00 & 100.00 \\
\hline
\end{tabular}

Table 2 (b)

Main Component Eigenvalues and Cumulative Contribution Rate of the Educational Structure of International Students in China Education from 2014 to 2015

\begin{tabular}{ccccc}
\hline \multirow{2}{*}{ Component } & \multicolumn{3}{c}{2014} & \multicolumn{2}{c}{2015} \\
\cline { 2 - 5 } & Eigenvalue & $\begin{array}{c}\text { Cumulative } \\
\text { contribution rate }(\%)\end{array}$ & Eigenvalue & $\begin{array}{c}\text { Cumulative } \\
\text { contribution rate }(\%)\end{array}$ \\
\hline 1 & 4.62 & 58.32 & 4.75 & 64.76 \\
2 & 1.11 & 74.01 & 1.07 & 70.98 \\
3 & 0.90 & 85.16 & 1.03 & 81.92 \\
4 & 0.46 & 93.85 & 0.60 & 92.90 \\
5 & 0.46 & 96.14 & 0.45 & 98.05 \\
6 & 0.21 & 98.99 & 0.19 & 99.35 \\
7 & 0.06 & 100.00 & 0.09 & 100.00 \\
8 & 0.00 & 100.00 & 0.00 & 100.00 \\
\hline
\end{tabular}

Table 2 (c)

Main Component Eigenvalues and Cumulative Contribution Rate of the Educational Structure of International Students in China Education from 2016 to 2017

\begin{tabular}{ccccc}
\hline \multirow{2}{*}{ Component } & \multicolumn{3}{c}{2016} & \multicolumn{2}{c}{2017} \\
\cline { 2 - 5 } & Eigenvalue & $\begin{array}{c}\text { Cumulative } \\
\text { contribution rate }(\%)\end{array}$ & Eigenvalue & Cumulative contribution rate $(\%)$ \\
\hline 1 & 4.99 & 58.01 & 4.84 & 59.50 \\
2 & 1.09 & 70.75 & 1.09 & 73.48 \\
3 & 1.01 & 82.82 & 0.91 & 82.63 \\
4 & 0.59 & 93.38 & 0.66 & 94.17 \\
5 & 0.38 & 96.28 & 0.47 & 96.54 \\
6 & 0.25 & 99.39 & 0.20 & 100.26 \\
7 & 0.01 & 100.00 & 0.08 & 100.00 \\
8 & 0.00 & 100.00 & 0.00 & \\
\hline
\end{tabular}

The third is the comprehensive score measurement of the educational structure of international students in China. By constructing the principal component equation model, the average score of the main components of the educational structure of international students from the host country of China's overseas engineering projects from 2010 to 2017 is calculated so as to rank overall educational development of international students in China from various host countries. The education structure is more reasonable for international students in China from countries with higher score and top ranking. The calculation results are shown in Table 3 . 
Wang, Tang / Research on the Educational Structure of International Students from the Host Country of China's Overseas ...

Table 3

Average Score and Ranking of the Main Components of the Educational Structure of International Students in China From 2010 to 2017

\begin{tabular}{|c|c|c|c|c|c|c|c|c|}
\hline Rank & Country & $\begin{array}{c}\text { Average } \\
\text { score }\end{array}$ & Rank & Country & $\begin{array}{c}\text { Average } \\
\text { score }\end{array}$ & Rank & Country & $\begin{array}{c}\text { Average } \\
\text { score }\end{array}$ \\
\hline 1 & Thailand & 5.30 & 22 & Nigeria & -0.03 & 43 & Libya & -0.51 \\
\hline 2 & Indonesia & 5.18 & 23 & Sudan & -0.05 & 44 & Ecuador & -0.57 \\
\hline 3 & Russia & 5.13 & 24 & Saudi Arabia & -0.06 & 45 & Afghanistan & -0.63 \\
\hline 4 & Pakistan & 3.53 & 25 & Algeria & -0.07 & 46 & Romania & -0.63 \\
\hline 5 & Kazakhstan & 3.41 & 26 & $\begin{array}{l}\text { United Arab } \\
\text { Emirates }\end{array}$ & -0.10 & 47 & Venezuela & -0.65 \\
\hline 6 & Malaysia & 3.32 & 27 & Bengal & -0.11 & 48 & Bulgaria & -0.68 \\
\hline 7 & India & 3.31 & 28 & Cambodia & -0.15 & 49 & Syria & -0.69 \\
\hline 8 & Mongolia & 3.31 & 29 & Philippines & -0.26 & 50 & Egypt & -0.72 \\
\hline 9 & Singapore & 3.30 & 30 & Vietnam & -0.27 & 51 & $\begin{array}{l}\text { Czech } \\
\text { Republic }\end{array}$ & -0.75 \\
\hline 10 & Myanmar & 3.27 & 31 & Mexico & -0.28 & 52 & Serbia & -0.76 \\
\hline 11 & Tajikistan & 3.09 & 32 & Sri Lanka & -0.33 & 53 & Slovakia & -0.78 \\
\hline 12 & Poland & 2.19 & 33 & Ethiopia & -0.33 & 54 & Georgia & -0.79 \\
\hline 13 & Iran & 2.11 & 34 & Bangladesh & -0.33 & 55 & Latvia & -0.80 \\
\hline 14 & Laos & 1.95 & 35 & Kenya & -0.34 & 56 & Azerbaijan & -0.81 \\
\hline 15 & Brazil & 1.84 & 36 & Angola & -0.34 & 57 & Armenia & -0.84 \\
\hline 16 & Kyrgyzstan & 1.70 & 37 & Hungary & -0.34 & 58 & Lithuania & -0.85 \\
\hline 17 & Nepal & 1.54 & 38 & Belarus & -0.38 & 59 & Israel & -0.86 \\
\hline 18 & Uzbekistan & 1.18 & 39 & Mali & -0.40 & 60 & Palestine & -0.87 \\
\hline 19 & Yemen & 1.17 & 40 & Turkey & -0.42 & 61 & Maldives & -0.87 \\
\hline 20 & Turkmenistan & 0.94 & 41 & Iraq & -0.44 & 62 & Greece & -0.92 \\
\hline 21 & Ukraine & 0.24 & 42 & Jordan & -0.48 & 63 & Slovenia & -1.00 \\
\hline
\end{tabular}

\section{Result analysis of the educational structure evaluation of international students in China}

The number of China's overseas engineering host countries is large and the geographical location, basic national conditions, education system and cultural characteristics of different countries will all influence the educational development of international students in China. Through the analysis of the evaluation results of the educational structure of international students in China, it is found that it presents the characteristics of single core and multi-level.

Single core. The size of international students in China is closely related to the hierarchical structure. The increase in scale promotes the optimization of academic structure and good academic education structure in turn has a positive impact on the size of international students in China. The principal component analysis also reflects that the countries with top ranking in educational structure of international students in China often have large scale of international students in China. Expanding the scale is the core factor for improving the comprehensive development level of the educational structure of international students in China and the key emphasis in work in the educational development of international students from the host country of China's overseas engineering projects is to adopt feasible policies and measures to expand the scale.

Multi-level. The comprehensive score of the educational structure of international students from the host country of China's overseas engineering projects show three distinct levels:

The first level includes Thailand, Indonesia, and Russia. The comprehensive score of these three countries in terms of the educational structure of international students in China are all greater than 5, which is significantly higher than other countries, which reflects the distinct predominance of these countries in the size, 
Wang, Tang / Research on the Educational Structure of International Students from the Host Country of China's Overseas ...

hierarchical structure and number of scholarships of international students in China.

The second level includes Pakistan, Kazakhstan, Malaysia, India, Mongolia, Singapore, Myanmar, and Tajikistan. The comprehensive score of the educational structure of international students in China is between 3 and 5, which is significantly higher than the remaining countries. Also, these countries are all in Asia, which shows that the geographical distance has a significant impact on the educational structure of international students in China.

The third level is the remaining countries with relatively backward education development in China, which mainly includes countries in Africa, Latin America, West Asia and Central and Eastern Europe. The factors restricting the development of international students in China from the above regions are rather complicated: the first is that the political and diplomatic relations have a profound influence on the educational and cultural exchanges between countries, which in turn affects the educational development of international students; the second is that the development level of higher education and population size also directly affect the education development of international students in China. It is worth noting that the education development of international students in China from Africa and Latin America, as key areas of China's engineering projects, is not optimistic. Therefore, it is necessary to increase the efforts in the education of international students in Africa and Latin America.

\section{Countermeasures for the development of educational structure for international students in China}

\section{Formulating cultivation direction oriented by the needs of the host country}

The key in the implementation process of China's overseas projects lies in the cultivation of talents, which is to realize the "hard connectivity" of infrastructure such as road traffic through the "soft connectivity" of cultural education. For the education of international students in China, colleges and universities can invest more resources in the following aspects based on the specific school conditions: the first is to implement the cultivation of professional technical talents. A large number of engineering and technical talents in different fields can be cultivated for the large-scale infrastructure construction in the host country of China's overseas projects through the education of international students in China. The second is to cultivate non-universal language talents. There are many official languages in the host country of China's overseas engineering projects and it is necessary to increase the cultivation efforts. The third is to lay emphasis on the cultivation of high-end overseas talents. The situation varies greatly from country to county and thus the high-end talents who are familiar with and understand both Chinese culture, their own countries and the comprehensive situation in their own region can create a good international space for China's national strategy and diplomatic strategy. The fourth is to vigorously develop national think tanks relying on the education of international students to strengthen the comprehensive research on the history, economy, politics, culture, and diplomacy of the host country of China's overseas engineering projects. 
Wang, Tang / Research on the Educational Structure of International Students from the Host Country of China's Overseas ...

\section{Striving for resources in various aspects based on the win-win cooperation philosophy}

Under the premise of the overall planning of the government, it is also very important to fully exploit various potential resources.

Overseas Chinese are the natural bridge and tie connecting China and the host country of China's overseas engineering projects. Government can play the leading role and give full play to the strength of overseas Chinese. Also, the host country education development funds can be established relying on the educational resources of colleges and universities to encourage and attract students in China to study in the host country of China's overseas engineering projects and outstanding students in the host country of China's overseas engineering projects to study in China, thus cultivating future leaders for developing countries. Many high-level universities in China can also go out and establish joint universities and research centres in the host country of China's overseas engineering projects to conduct Sino-foreign joint education.

Some universities in China have established Confucius Institutes in the host country of China's overseas engineering projects and according to the educational needs of different countries, they can set up Confucius Institutes with different characteristics combined with the school-running characteristics of each school; also, they can cooperate with the host government to jointly set up special funds for education aid to expand the education assistance for developing countries, thus cultivating leader and management talents, teachers and technical talents of all levels and professions.

\section{Deeply ploughing the target country and conducting accurate recruitment}

The centripetal force of Chinese culture, the potential of Chinese market and the comparative advantage of China's higher education are the main motivation for students from neighbouring developing countries to study in China. Many multilateral cooperation mechanisms can be found in the host countries such as the Shanghai Cooperation Organization (SCO), the Asia-Pacific Economic Cooperation (APEC), the Asia-Europe Meeting (ASEM), Conference on Interaction and Confidence-Building Measures in Asia (CICA) and Central Asia Regional Economic Cooperation (CAREC). Every country and region have its own demand for talents, which requires universities to make some efforts to formulate mid-and-long term development plans for international students and study the demand for talents of neighbouring countries. For example, ASEAN countries focus on infrastructure construction; Central Asian countries focus on energy and transportation development and coastal countries focus on port facilities and marine ship machinery. After clarifying these demands, we can conduct international recruitment publicity to attract international students based on the advantages of the school. In addition, special attention should be paid to the recruitment of high-level talents including master and doctoral students. Graduate students, especially the doctoral students play a very important role in the economic construction and social development of all countries. The cultivation of high-end talents who understand Chinese culture, master Chinese technology and are friendly to China will play a greater role in radiation and dissemination. 
Establishing scholarships to attract students from the host country of China's overseas engineering projects

Many of the host countries of china's overseas engineering projects are developing countries with relatively low economic level, so the economic affordability of students is weak. If a special scholarship can be established, it is very attractive to international students. Many provinces and schools are aware of this and have established special scholarships. For example, Sichuan University has fully utilized the geographical advantage of opening up to the west and south and "the Belt and Road" construction. In 2016, Sichuan University firstly established "the Belt and Road" scholarship, with the total amount of 100 million yuan, for international students in China all universities in China. Since 2016, the Shaanxi Provincial Party Committee and the Provincial Government have increased the amount of the "Three Qin Scholarship for International Students in China" and inclined to the countries and regions along the Silk Road, especially in Central Asia and West Asia. In addition, Chongqing, Hubei, Hunan, and Fujian Qinghai and Xinjiang Provinces also offer national or language special scholarships for different countries. It is foreseeable that with the support of relevant scholarships, more international students will have the opportunity to study in China and realize their Chinese dream.

\section{References}

Chen, L., \& Eliman, A. (2016). Study on the development and strategies for the education of students from countries along 'the belt and road' in China in recent decade. Comparative Education Research, 38(10), 27 36.

Easley, J. A., Piaget, J., Rosin, A. (1980). The development of thought: equilibrium of cognitive structures. Brain Research, 486(1), 175-180. http://dx.doi.org/180. 10.1016/0006-8993(89)91291-2

Han, L. L. (2017). How to improve competitiveness of education for foreign students in China: From the perspective of scale and degree structure. Journal of Beijing Normal University (Social Science), (5), 18-30. http://doi.org/10.3969/j.issn.1002-0209.2017.05.002

He, B. S. (2007). International Engineering Contracting (Second Edition). China Building Industry Press.

Hu, R., Yu, S. C. (2018). Evaluation and development of the overseas students along the belt and road in China. Journal of Hebei Normal University (Educational Science), (5), 68-73. http://doi.org/10.13763/j.cnki.jhebnu.ese.2018.05.010

Song, Y. (2007). On the audit of overseas general contracting projects. International Engineering and Labor, (7), 29-31.

Yang, J. R., \& Lu, X. R. (2018). Analysis of China's international engineering contractors' "going out" country selection problem. Science and technology economic market, (7), 68-70.

Zhang, L. J. (2017). China's country selection and effect analysis for the "Belt and Road" industry transfer. Doctoral dissertation, Shandong Normal University. 